\title{
ANÁLISE DA INTERSETORIALIDADE NO PLANO DE SANEAMENTO BÁSICO DE PARAGOMINAS-PA.
}

Ruana Regina Negrão De Souza-ruengamb@gmail.com Universidade Do Estado Do Pará

Ana Claudia De Sousa Da Silva - anahxua_13@ hotmail.com Universidade do Estado do Pará

Mário Marcos Moreira Da Conceição - mariomarcomc.7@gmail.com Universidade do Estado do Pará

Estefani Danielle Barros De Araújo-barrosestefani@gmail.com Universidade do Estado do Pará

Daniellen Teotonho Barros - daniellen.engamb@gmail.com Universidade do Estado do Pará 


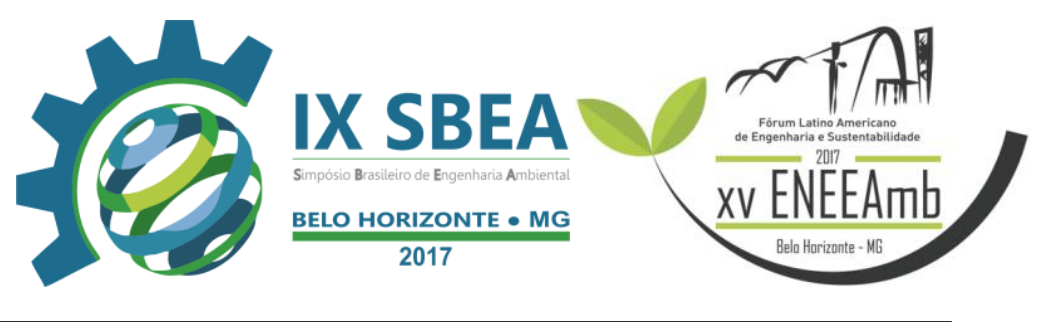

\section{RESUMO}

O Saneamento Básico e a saúde pública vêm sendo negligenciados como instrumentos de planejamento, o que exige novas posturas na gestão das políticas públicas. Neste contexto, a articulação, através das ações intersetoriais é utilizada como forma de proporcionar benefícios e serviços de saúde e assistência social aos seus usuários. O objetivo deste trabalho é analisar a visão dos gestores quanto, a intersetorialidade dos órgãos de saneamento básico do município de Paragominas-Pará. A metodologia adotada foi através de análise qualitativa e aplicação de entrevistas semiestruturadas, referente ao tema e sucessiva descrição acompanhada de uma posterior análise dos dados coletados, com gestores dos principais órgãos públicos responsáveis pelo setor de saneamento básico do município. Os resultados obtidos mostram que os gestores compreendem a importância da intersetorialidade e são conscientes, que esta é feita de forma remediadora com base nos problemas obtidos em relação aos quatro eixos de saneamento acarretando maiores custos para o município de Paragominas.

Palavras-chave: Políticas Púbicas, Gestão, Saneamento Básico.

\section{INTRODUÇÃO/OBJETIVO}

A problemática urbana resulta, entre outras causas, da diversidade de impactos ambientais e das diferentes medidas através das quais se procura solucionar tais impactos. Dentre estas medidas o saneamento básico, torna-se essencial para a melhoria da qualidade de vida da população e preservação dos recursos naturais, podendo ser definido como um conjunto de medidas mitigadoras que visam preservar ou modificar as condições do meio ambiente, com o objetivo de prevenir doenças e promover a saúde da população (GODECKE \& DECKER, 2014).

Ademais, o saneamento também pode ser entendido como o controle de todos os fatores do meio físico do homem, que exercem ou podem exercer efeitos nocivos sobre o bem estar físico, mental e social. Neste enfoque, o saneamento tem por objetivo minimizar os danos ao meio ambiente que interferem na saúde da população. Dessa forma, pode-se dizer que saneamento caracteriza o conjunto de ações socioeconômicas que têm por finalidade alcançar salubridade ambiental. Além disso, é fator essencial para saúde, economia e produção de um país (VALDEVINO et al., 2010). 


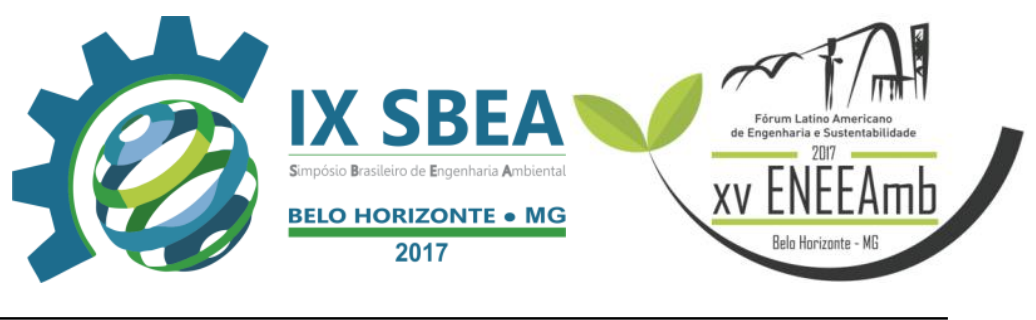

No entanto, o saneamento ambiental e a saúde pública vêm sendo negligenciados como instrumentos de planejamento, o que exige novas posturas na gestão das políticas públicas, na qual a participação popular e o controle social devem estar interligados e os setores de gestão responsáveis pelo saneamento dos municípios, relacionados no que se chama de intersetorialidade, haja vista que este é um direito assegurado pela constituição federal e definido pela Lei Federal do Saneamento Básico, n. 11.445:2007 (PHILIPPI JÚNIOR, 2005).

Não obstante, observa-se que no decorrer do processo de descentralização dos serviços públicos pós Constituição Federal de 1988, sobretudo, no âmbito da saúde e da assistência social, a intersetorialidade e a articulação representam um tema complexo e desafiador que, apesar de fazerem parte do ideal a ser alcançado pelos gestores das políticas públicas, não estão contemplando essas áreas da forma como vem sendo proposto nos marcos regulatórios dessas políticas. Então, a articulação, através das ações intersetoriais é utilizada como forma de proporcionar benefícios e serviços de saúde e assistência social aos seus usuários (COMERLATTO et al., 2007; JUNQUEIRA, 1998; ORNELAS \& TEIXEIRA, 2015).

Sabe-se, ainda que a situação dos serviços de saneamento no Brasil continua bastante precária ao longo dos anos, em virtude das deficiências nas políticas públicas de saneamento vigentes até o momento. Além da suposta carência de recursos públicos para investimentos em obras de tal porte (LEONETI et al., 2011). O cenário do saneamento básico em nível nacional sugere a necessidade de uma avaliação não apenas global, mas também local das características de tais dados, uma vez que, a realidade muda bastante entre as diversas regiões brasileiras. Assim, aumentam as possibilidades de se criarem estratégias mais eficientes de melhoramento no quadro de saneamento ambiental no país (CARVALHO \& ADOLFO, 2012).

Nessa perspectiva, a opção pelo processo de intersetorialidade remete à noção de que as políticas públicas não podem desenvolver-se, de forma desarticulada e permite uma abordagem, de maneira ampla da problemática social em seu caráter complexo, bem como multidimensional, se inserindo em vários âmbitos do atual contexto político, econômico e social. Portanto, o presente trabalho tem como objetivo analisar a percepção dos gestores de saneamento do município de Paragominas quanto à intersetorialidade como ferramenta para o desenvolvimento do sistema de saneamento já existente.

\section{METODOLOGIA}

\section{1-ÁREA DE ESTUDO}




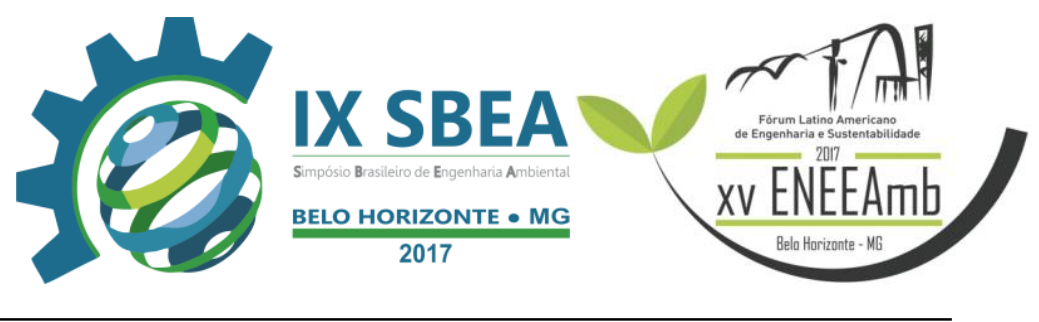

O município de Paragominas situado às margens da rodovia Belém-Brasília (BR-010) está localizado na mesorregião nordeste do Pará, há 320 quilômetros da cidade de Belém, possui uma área de 19.342,254 quilômetros quadrados e uma população estimada de 107,010 resultando em uma densidade demográfica de 5,06 habitantes por quilômetro quadrado. Tem como limite os municípios paraenses: Ipixuna do Pará, Nova Esperança do Piriá, Ulianópolis, Goianésia do Pará e Dom Eliseu (IBGE, 2010).

Caracteriza-se por ter um clima tropical chuvoso com estação seca bem definida. A temperatura média anual é elevada, em média de $26.5^{\circ} \mathrm{C}$, e máxima de $35^{\circ} \mathrm{C}$. O regime pluviométrico anual corresponde a $2250 \mathrm{~mm}$, mas não se distribui regularmente durante o ano. Os meses de julho a dezembro correspondem aos dias mais quentes, enquanto de janeiro a junho, o período mais frio (EMBRAPA, 2003).

\subsection{MÉTODOS}

Optou-se por fazer análise de forma qualitativa, através da aplicação de entrevistas semiestruturadas referente ao tema e sucessiva descrição, acompanhada de uma posterior análise dos dados coletados com gestores dos principais órgãos públicos que tratam do saneamento básico do município de Paragominas.

A aplicação de questionário conduz à coleta de dados reais, que de forma precisa busca por dificuldades existentes na rede de saneamento básico do município. A coleta de dados com a entrevista direta, em senso de relatos descritos, foi realizada com gestores representantes da Agência de Saneamento de Paragominas (SANEPAR), Secretaria Municipal do Verde e do Meio Ambiente (SEMMA) e da Secretaria Municipal de Saúde(SEMS) (figura 1). 

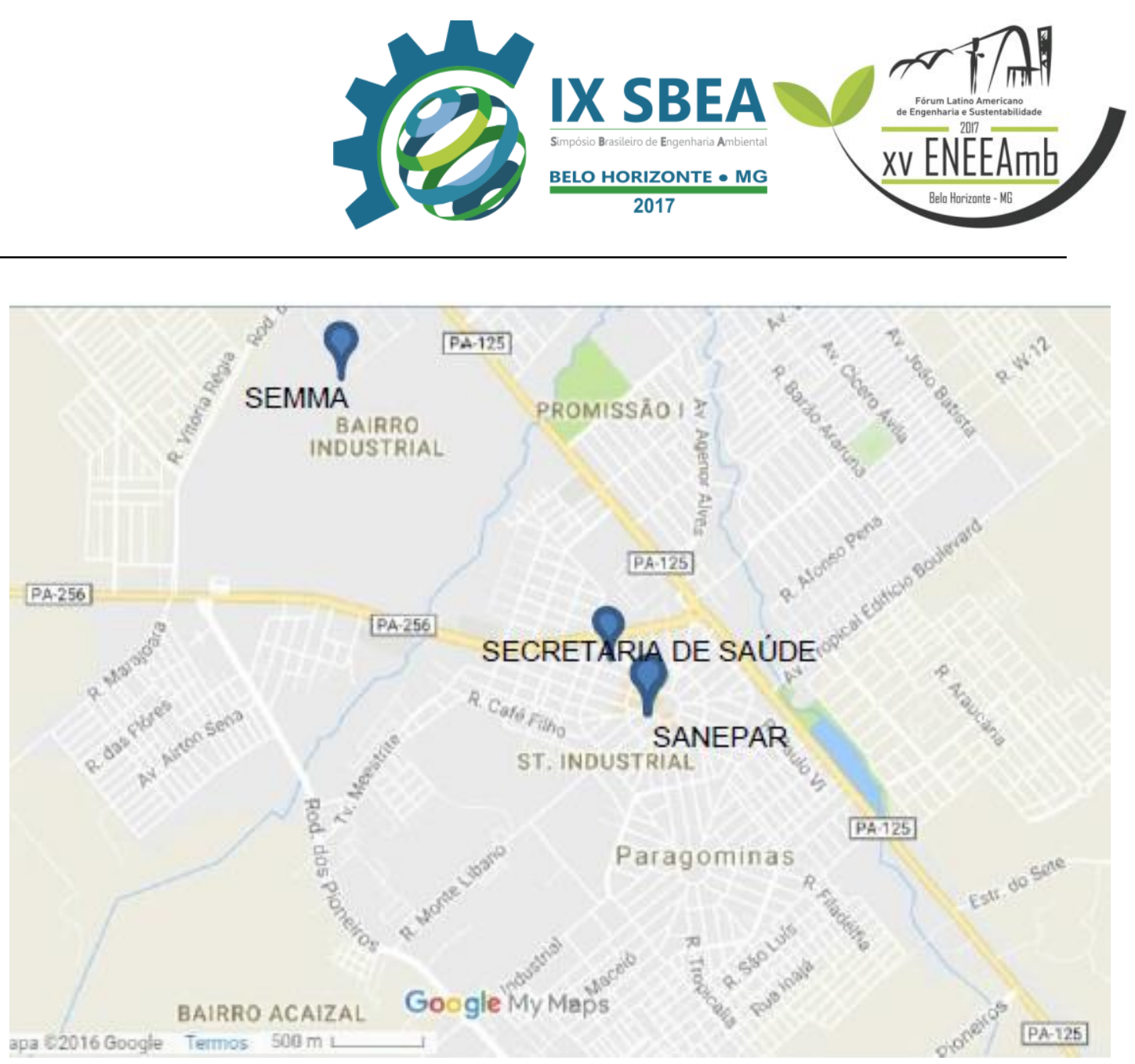

Figura 01: Localização dos órgãos municipais de saneamento de Paragominas. Fonte: Google Earth, 2016.

A entrevista consistiu com sete perguntas relacionadas ao saneamento básico prestado ao município, relacionando este a intersetorialidade como ferramenta para um melhor engajamento dos setores de saneamento. As perguntas envolviam temas desde o conhecimento de termo intersetorialidade, fatores que contribuem ou prejudicam essa relação intersetorial, a existência de mecanismos para essa integração e as oportunidades perdidas pela falta deste engajamento.

A análise iniciou-se com a transcrição dos dados coletados por gravações e sucessiva exploração do conteúdo, os discursos dos entrevistados foram reunidos e direcionados a uma única preleção. Buscou-se, selecionar as ideias centrais com as palavras chaves de cada entrevistado sintetizou-se, todo conteúdo.

\section{RESULTADOS E DISCUSSÃO}

De acordo com todas as respostas dos gestores, pode-se obter resultados quanto a intersetorialidade, referente aos quatros eixos do saneamento básico, se essa é utilizada ou não, como ferramenta para contribuir com o desenvolvimento do município de Paragominas. 


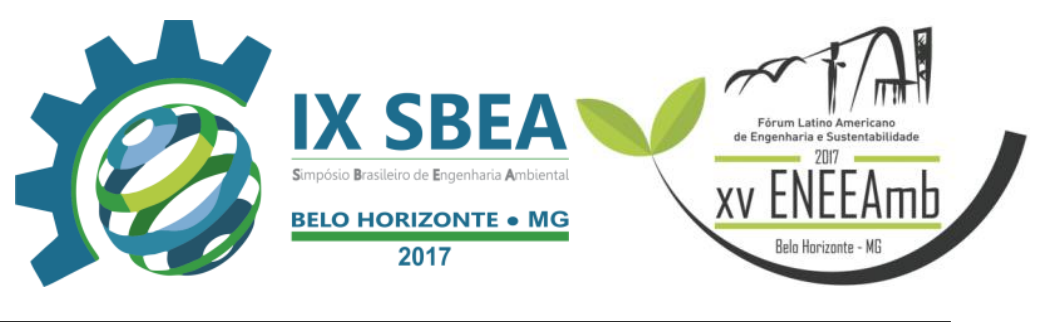

Os entrevistados apresentam cargos diferenciados em três setores municipais, apresentando diferentes opiniões em relação ao saneamento básico. A maioria dos entrevistados são responsáveis pelos quatro eixos do saneamento básico, alguns pelo gerenciamento dos resíduos sólidos e drenagem, outros pelo abastecimento de água e esgotamento sanitário, e os demais são responsáveis pela saúde pública do município.

A partir, das perguntas feitas aos gestores em relação ao conceito de intersetorialidade e a importância desta para os avanços da qualidade de vida do município, foi citado que essa é um bem necessário envolvendo o abastecimento de água, esgotamento sanitário, gerenciamento dos resíduos sólidos e a drenagem de águas pluviais, que são serviços prestados pela SANEPAR, Secretária de Urbanismo e a Secretária de Infraestrutura do município de Paragominas.

Em relação às reuniões, mecanismos e os incentivos atraídos para a integração, um dos entrevistados comentou que "não possui um número definido, há sempre encontros entre os secretários e o prefeito para a discussão de política”. Os atores envolvidos, dependendo dos problemas detectados, podendo ser a secretaria de Meio Ambiente, SANEPAR, Secretaria de Educação, Secretaria de Obras. Inclusive, o município possui o conselho de saneamento e de meio ambiente, mas não há reuniões frequentes, somente quando há alguma pauta específica para discussão.

Na elaboração do Plano Municipal de Saneamento Básico, houve a integração dos diversos setores, abrangendo os quatros eixos de saneamento que hoje caracterizam o saneamento básico, trabalhando inicialmente sobre o diagnostico em relação às mazelas de abastecimento de água, identificando todos os setores de distribuição com reservatórios e linhas de distribuição, a descrição do esgotamento sanitário e a população que recebe esse sistema.

No prognóstico do plano, foi dividido em curto, médio e longo prazo. Em curto prazo foi feito, a relação ao fornecimento de água em diversos bairros do município. Em médio prazo, tem-se a aplicação da estação de tratamento de água com um projeto pronto que vai atender todo o município de Paragominas, incluindo toda a zona urbana e rural. Em longo prazo, contempla projetos de todos os loteamentos residenciais particulares que se instalarem em Paragominas, será necessário ter a estação de tratamento de esgoto.

Portanto, a secretaria de infraestrutura impõe pontos às obras de macro e micro drenagem que iriam realizar nos próximos anos, se realizará ou não o remanejamento da 


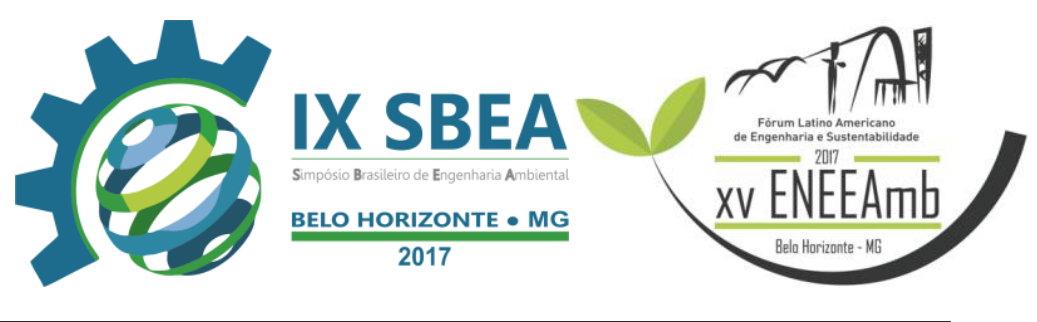

população de uma determinada área que sofre com alagamentos. A secretaria de urbanismo trabalhou a questão de gerenciamento de resíduos sobre adoção da coleta seletiva, logística reversa, levando em consideração a Política Nacional dos Resíduos Sólidos.

\section{CONCLUSÕES/RECOMENDAÇÕES}

Diante disso, nota-se que a intersetorialidade existente entre os eixos do saneamento básico do município de Paragominas, é apenas de forma remediadora e não preventiva, não sendo eficaz a sua aplicação, como ferramenta para o desenvolvimento do saneamento já existente no município, pois só há integração dos setores quando surgem problemas no município relacionados ao saneamento. Dessa maneira, as reuniões são feitas com base nos problemas que devem ser resolvidos e consequentemente gera mais custos para a Prefeitura de Paragominas, o que leva a acreditar que o planejamento não acontece como convicção dos seus reais benefícios.

Deste modo, as ações de saneamento básico, se configuram em serviços públicos essenciais de obrigação do Estado, mais especificamente na instância municipal. Logo, cabe ao poder público dos municípios a responsabilidade de acompanhar, fiscalizar e definir as políticas e os programas a serem efetivados. Por outro lado, os cidadãos, usuários dos serviços de saneamento ambiental, não devem atuar neste contexto como sujeitos passivos, encarregados unicamente de esperar as execuções municipais para melhorar ou piorar suas respectivas qualidades de vida. Pelo contrário, devem opinar cobrar e fiscalizar as ações do poder público efetuando seu papel na participação e integralidade com o poder público.

É necessário ressaltar que a sociedade assume importante papel para a formulação e execução das políticas públicas em todos os campos e esferas. Ou seja, os cidadãos devem abandonar o pensamento que restringe a execução de obras de saneamento unicamente pelos gestores públicos e adotar a ideia de constituir, juntamente com as instâncias governamentais, uma ação que, a partir da participação integrada, almeje benefícios mútuos, cujo objetivo maior seria a preservação da qualidade ambiental.

Assim, para que haja um bom funcionamento dos componentes integrantes do saneamento básico, é de fundamental relevância o engajamento intersetorial dos vários órgãos de saneamento para a construção e de tomadas de decisão durante sua formulação, tornando-se imprescindível a sua participação no planejamento político em todas as etapas. 


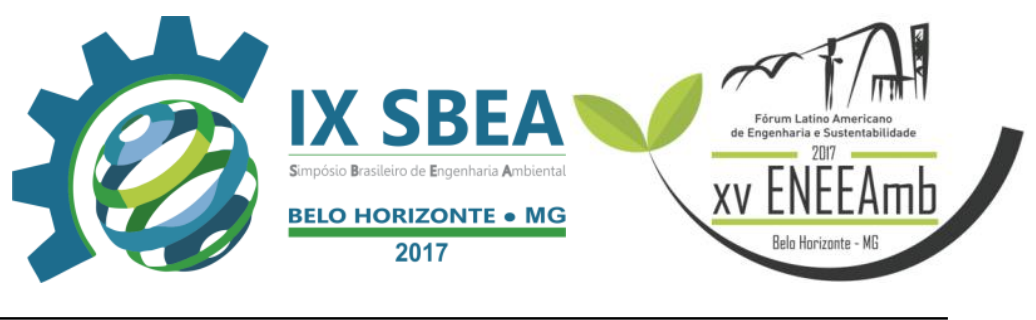

Este engajamento é tido como imprescindível para os gestores entrevistados. No entanto, a efetividade da aplicação deste termo no planejamento de saneamento do município não é efetiva. Por isso, é necessário que se tenha clareza de sua importância prática e conceitual, pois se trata de ação que representa a melhor forma de articulação dos vários saberes e fazeres que interferem na vida em sociedade.

\section{REFERÊNCIAS BIBLIOGRÁFICAS}

CARVALHO, S.A.; ADOLFO, L. G. S. O direito fundamental ao Saneamento Básico como garantia do mínimo existencial social e ambiental. Revista Brasileira de Direito, Passo Fundo, v. 8, n. 2, p. 6-37, jul. 2012.

COMERLATTO, D. et al. Gestão de políticas públicas e intersetorialidade: diálogo e construções essenciais para os conselhos municipais. Revista Katálysis, Florianópolis, v. 10, n. 2, p.265-271, jul. 2007.

EMBRAPA, Agência de Informação Embrapa, 2003. Disponível em:< https://www.embrapa.br/busca-de-publicacoes/-/publicacao/408067/caracterizacao-e classificacao-dos-solos-do-municipio-de-paragominas-estado-do-para>. Acesso em: 26 fev. 2017.

GODECKE, M. V.; DECKER, A. T. Saneamento básico: estudo de caso de Arroio Grande, RS. REGET, Santa Maria, v. 18, n. 4, p. 1371-1388, dez. 2014.

INSTITUTO BRASILEIRO DE GEOGRAFIA E ESTATÍSTICA (IBGE). Cidades. Paragominas-PA.

Disponível em: $<$ http://cidades.ibge.gov.br/xtras/perfil.php?lang=\&codmun=150550\&search=para|parago minas > Acesso em: 1 mar. 2017.

JUNQUEIRA, L. A. P. Descentralização e intersetorialidade: a construção de um modelo de gestão municipal. Revista de Administração Pública, Rio de Janeiro, v. 32, n. 2, p.11-22, mar. 1998.

LEONETI, A. B. et al. Saneamento básico no Brasil: considerações sobre investimentos e sustentabilidade para o século XXI. Revista de Administração Pública, Rio de Janeiro, v. 45, n. 2, p.331-348, mar. 2011.

ORNELAS, A. L.; TEIXEIRA, M. G. C. Intersetorialidade ou diálogos setoriais? Reflexões a partir da experiência do Projeto Teias-Escola Manguinhos, Rio de Janeiro. Revista Saúde em Debate, Rio de Janeiro, v. 39, n. 106, p.659-670, jul. 2015. 


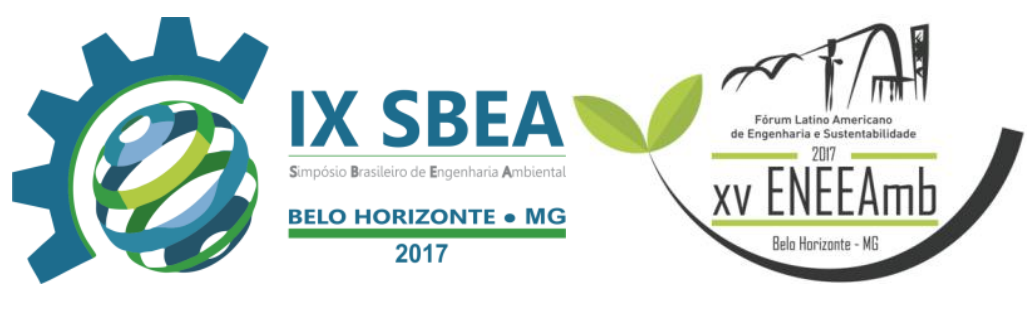

PHILIPPI JUNIOR, A. Saneamento, Saúde e ambiente: Fundamentos para um desenvolvimento sustentável, $2^{\circ}$ ed. Barueri: Manoele, 2005.248 p.

VALDEVINO, A. A. F. et al. Avaliação da eficiência dos serviços de saneamento básico no combate às endemias nos municípios do Estado do Tocantins. Informe Gepec, Toledo, v. 14, n. 2, p.166-181, dez. 2010. 